\title{
Assessment of in-situ abundance dynamics of enterobacteria and total heterotrophic aerobic bacteria in groundwater in the equatorial region of Central Africa
}

\author{
Moïse Nola1*, Jean Samuel Eheth', Mireille E Nougang1', Marlyse L Moungang1', Olive V Noah Ewoti', \\ François Krier ${ }^{2}$, Nour-Eddine Chihib ${ }^{2}$, Pierre Servais ${ }^{3}$, Jean-Pierre Hornez ${ }^{2}$ and Thomas Njiné ${ }^{1}$ \\ 1 University of Yaounde 1, Faculty of Sciences, Laboratory of General Biology, PO Box 812 Yaounde, Cameroon \\ 'Université des Sciences et Technologies de Lille 1, Laboratoire ProBioGEM, Bâtiment Polytech' Lille, Bd Paul Langevin \\ - Cité Scientifique, 59655 Villeneuve d'Ascq cedex France \\ ${ }^{3}$ Université Libre de Bruxelles, Ecologie des Systèmes Aquatiques, Campus de la Plaine CP 221, Boulevard du Triomphe, \\ 1050 Bruxelles, Belgique
}

\begin{abstract}
The main purpose of this investigation was to assess, in situ, the hourly abundance dynamics of enterobacteria and total heterotrophic aerobic bacteria (THAB), over a daily period, in 3 wells in Yaounde region, Cameroon. Sampling was done weekly, for 4 months. Water samples were collected in sterile glass bottles and incubated in situ for $2 \mathrm{~h}, 4 \mathrm{~h}, 6 \mathrm{~h}, 8 \mathrm{~h}, 10 \mathrm{~h}$ and $12 \mathrm{~h}$. Isolation and enumeration of enterobacteria and THAB were performed on MacConkey agar (Bio-Rad) and standard agar (Bio-Rad) media, respectively, using the plate count method. Using a linear regression model, ln(number of CFUs) was plotted against time. The slope of each regression line was considered as the apparent increase or decrease in cell number. Concentrations of THAB and enterobacteria varied from 9.90 to 14.19 and 4.09 to $9.59 \ln$ units $\mathrm{m}^{-1}$, respectively, in W1, from 9.90 to 14.25 and 3.00 to $5.39 \ln$ units $\ell^{-1}$ in $\mathrm{W} 2$, and from 9.90 to 14.00 and 6.55 to $11.51 \mathrm{ln}$ units $\cdot \mathrm{m}^{-1}$ in $\mathrm{W} 3$. For the first 6-hour incubation period at all of the sampling points, the cell apparent growth rate (CAGR) varied from 0.023 to $0.262 \mathrm{~h}^{-1}$ for THAB and from 0.001 to $0.315 \mathrm{~h}^{-1}$ for enterobacteria; cell apparent inhibition rate (CAIR) varied from 0.015 to $0.615 \mathrm{~h}^{-1}$ for THAB and from 0.015 to $0.604 \mathrm{~h}^{-1}$ for enterobacteria. In the second 6-h incubation period, the CAGR varied from 0.010 to $0.822 \mathrm{~h}^{-1}$ for THAB and from 0.015 to $0.771 \mathrm{~h}^{-1}$ for enterobacteria; the CAIR varied from 0.015 to $0.260 \mathrm{~h}^{-1}$ for THAB and from 0.007 to $0.338 \mathrm{~h}^{-1}$ for enterobacteria. The values of physico-chemical parameters recorded before incubation displayed temporal and spatial variation over the sampling period. Bacterial abundance dynamics in some cases was significantly correlated to some of these abiotic factors. The abundance of the microorganisms decreased initially but later increased.
\end{abstract}

Keywords: enterobacteria, THAB, growth rate, inhibition rate, groundwater, chemical

\section{Introduction}

Groundwater is present in the pores between soil or rock particles. When all of the pores are filled up and the soils and rocks are saturated, an aquifer is formed. While surface waters are easily polluted, groundwater is protected by the soil that covers it, which also acts as a filter for wastewater infiltration. Due to the absence of light the production of organic matter (photosynthesis, chemosynthesis) by autotrophic micro-organisms is excluded, organic carbon and other nutritive substances such as nitrogen and phosphorus are often present in low concentrations, and with relatively low temperatures and dissolved oxygen contents, groundwater has for a long time been considered as an unfavourable environment for microbial life (Gilbert et al., 1994). The origin of bacteria in underground water is often debated. Fenchel (2001) postulated that the ancestors of native underground ecosystems could have originated from a probable mutation of anoxigenic microorganisms. Other authors claim that, although the origin of some micro-organisms is uncertain, most underground bacteria derive from propagated infiltrated bacteria emanating from pollution of underground water by runoff (Mayer et al., 1997; Dzeda et al., 1998).

\footnotetext{
* To whom all correspondence should be addressed. 푤 +237994326 39; e-mail: moise.nola@yahoo.com Received 10 December 2009; accepted in revised form 5 October 2012.
}

Several studies have been carried out on the microbial quality of groundwater in various regions around the world. In the equatorial region of Central Africa it has been indicated that groundwater harbours stygobiontic fauna of various taxa (Zébazé Togouet et al., 2009). The isolated bacteria species include commensal species, and pathogenic as well as opportunistic species; their distribution undergoes fluctuations in space and time, and is sometimes influenced by physicochemical and meteorological factors (Nola et al., 2001, 2002). However, it is unclear whether the temporal variation in their abundance results from dilution by infiltrated water or, augmentation of bacteriological pollutants, or if it is related to death or cell growth in situ. Little data are available on daily bacterial dynamics in groundwater. Some authors in other regions of the world have indicated the potential heterotrophic activity of bacteria adhering to geological particles in groundwater (Alfreider et al., 2001). The purpose of this investigation was to assess, over a daily period, the hourly in situ fluctuation in abundance of enterobacteria and heterotrophic bacteria in wells without flux renewal, in the equatorial region of Cameroon (Central Africa).

\section{Materials and methods \\ Description of study sites}

The Yaounde region is located at latitude $3^{\circ} 52^{\prime} \mathrm{N}$, longitude $11^{\circ} 32^{\prime} \mathrm{E}$ and has an altitude of about $760 \mathrm{~m}$ amsl. The climate 
is typically equatorial, with 4 unequal seasons (Succhel, 1972). A mild rainy season from April to June, a mild dry season from July to August, a peak rainy season from September to November and a peak dry season from December to March. Soil is ferro-lateritic and acidic, the $\mathrm{pH}$ values in general being lower than 6 (Bachelier, 1959). Three well water points coded $\mathrm{W} 1, \mathrm{~W} 2$ and W3 were chosen, based on their importance as a drinking water supply for the communities, the higher density of the neighbouring communities and the permanent presence of water in these wells during all seasons of the year. The depths of the wells were: $420 \mathrm{~cm}, 405 \mathrm{~cm}$ and $410 \mathrm{~cm}$ for $\mathrm{W} 1$, W2 and W3, respectively. During the experimental period use of these wells by the communities was temporarily halted for a period of $24 \mathrm{~h}$. Each well point was sampled once a week. The study was carried out from April to July 2009 and weeks were numbered 1 to 17 .

\section{Water sampling and assessment of bacterial abundance}

At each well point on the sampling day, the water temperature and the water column thickness were measured. The water was initially collected in a $500 \mathrm{~m} \ell$ sterile glass bottle labelled $\mathrm{T}$, and in a $1000 \mathrm{~m} \ell$ clean polyethylene bottle. A volume of $500 \mathrm{~m} \ell$ of each sample was introduced in 3 series of 6 sterile glass bottles labelled A, B, C, D, E and F. Each of these bottles was attached to a thin sterilised wire and was immersed in the water column in the same wells at 6:00, thus incubated in situ. The sample labelled $\mathrm{T}$ and that in the polyethylene bottle were transported to the laboratory at $4^{\circ} \mathrm{C}$, for bacteriological and physico-chemical analyses, respectively.

The 3 samples labelled A were removed from the well column after $2 \mathrm{~h}$ of incubation. While the remaining bottles labelled B, C, D, E and F were removed from the well after $4 \mathrm{~h}$, $6 \mathrm{~h}, 8 \mathrm{~h}, 10 \mathrm{~h}$ and $12 \mathrm{~h}$ of incubation, respectively. Each sample was immediately transported to the laboratory on ice for bacteriological analysis of the enterobacteria and total heterotrophic aerobic bacteria (THAB). The enumeration of enterobacteria and THAB was performed on MacConkey agar (Bio-Rad) and standard agar (Bio-Rad) media, respectively, using the plate count method (Marchal et al., 1991). The Gram staining and biochemical identification (including the use of D-glucose and nitrate, production of indole, presence or absence of catalase and oxidase) of enterobacteria were carried out according to Holt et al. (2000). Bacterial abundance was expressed as the number of colony forming units (CFUs) per $\mathrm{m} \ell$ of water.

The physico-chemical parameters considered were temperature, $\mathrm{pH}$, electrical conductivity, total suspended solids (TSS), colour, turbidity, $\mathrm{CO}_{2}, \mathrm{NH}_{4}^{+}$and BOD5. These parameters were chosen in accordance with the availability of laboratory reagents and their general importance for the bacterial survival in groundwater. The analysis was performed using standard methods (Rodier, 1996; APHA, 1998) and was carried out only on water sampled at 6:00 on the sampling day.

\section{Data analysis}

The average values for the number of CFUs obtained from each water sample for each group of bacteria considered were transformed into $\ln$ units. The mean values of the bacterial abundances with respect to the sampling week number (numbered from 1 to 17) were illustrated by semi-logarithmic histograms. Ln(number of CFUs) was plotted against duration for each site during each sampling period. The incubation period was divided in 2 sub-periods: from the initial moment up to the $6^{\text {th }}$ hour (from 6:00 to $12: 00$ ), and from the $6^{\text {th }}$ hour up to the $12^{\text {th }}$ hour (from 12:00 to 18:00). Graphs were then plotted for each of the two sub-periods considered.

Each straight regression line equation $(y=a x+b)$ was calculated using the method of least squares (Bailey, 1981; Tofallis, 2009). In this equation: $y$ is the $\ln$ (number of CFUs), $x$ is the incubation duration $(2 \mathrm{~h})$. The straight regression line obtained is equated with the exponential phase, for example, that of bacterial growth in non-renewed culture medium. The slope $a$ of each regression line was considered to be the cell apparent dynamics for $2 \mathrm{~h}$. Since the frequency with which samples were removed from the wells was every $2 \mathrm{~h}$, each slope value was divided by 2 to obtain the hourly value for the apparent cell dynamics. This was compared to the cell apparent growth rate (CAGR), when positive, or to the cell apparent inhibition rate (CAIR) when negative. The Spearman correlation test was performed between the cell abundance dynamics and physico-chemical parameters recorded at the initial sampling time. The absolute values of CAIR were considered in this assessment. All calculations were performed using the SPSS 12.0 programme.

\section{Results}

\section{Physico-chemical and hydrological characteristics}

Water column thickness ranged between 166 and $214 \mathrm{~cm}$ (Fig. 1), and water temperature between 19 and $20^{\circ} \mathrm{C}$. Turbidity in W1 varied from 1.2 to $7.7 \mathrm{NTU}$, and in Wells W2 and W3 varied from 1.4 to $32.4 \mathrm{NTU}$, and 1.8 to $103 \mathrm{NTU}$, respectively (Fig. 1). The highest concentration of TSS was $10 \mathrm{mg} \cdot \ell^{-1}$ in Well $\mathrm{W} 1,30 \mathrm{mg} \cdot \ell^{-1}$ in Well W2 and $102 \mathrm{mg} \cdot \ell^{-1}$ in Well W3. The presence of TSS was sometimes rare in W1 (Fig. 1). Water colour reached $37 \mathrm{PtCo}$ in Well W1, 152 PtCo in Well W2, and 494 PtCo in W3. In Well W1, water was sometimes colourless (Fig. 1). The $\mathrm{pH}$ values ranged between 5.45 and 6.04 in Well W1, between 4.93 and 5.35 in Well W2 and between 6.87 and 8.04 in Well W3. The highest concentration of dissolved $\mathrm{CO}_{2}$ for the three wells was $15.84 \mathrm{mg} \cdot \ell^{-1}$. The lowest concentration was $8.8 \mathrm{mg} \cdot \ell^{-1}$ for Wells W1 and W2 and $7.04 \mathrm{mg} \cdot \ell^{-1}$ for Well W3 (Fig. 1). The electrical conductivity fluctuated between 445 and $525 \mu \mathrm{S} \cdot \mathrm{cm}^{-1}$ in $\mathrm{W} 1$, between 244 and $272 \mu \mathrm{S} \cdot \mathrm{cm}^{-1}$ in W2, and between 524 and $767 \mu \mathrm{S} \cdot \mathrm{cm}^{-1}$ in W3 (Fig. 1). The concentration of $\mathrm{NH}_{4}^{+}$varied from 2.65 to $5.05 \mathrm{mg} \cdot \ell^{-1}$ in W1, 2.42 to $3.94 \mathrm{mg} \cdot \ell^{-1}$ in W2 and from 5.1 to $10.2 \mathrm{mg} \cdot \ell^{-1}$ in $\mathrm{W} 3$. The BOD5 values ranged between 10 and $125 \mathrm{mg} \cdot \ell^{-1}$ in $\mathrm{W} 1$, between 5 and 25 $\mathrm{mg} \cdot \ell^{-1}$ in W2 and between 5 and $100 \mathrm{mg} \cdot \ell^{-1}$ in Well W3 (Fig. 1).

\section{Bacteriological characteristics}

\section{Temporal variation in the concentration of THAB}

In Well W1, the abundance of THAB at the initial time ranged from 9.90 to $14.19 \ln$ units $\mathrm{m}^{-1}$ (Fig. 2). The abundance of THAB underwent temporal variations during the incubation periods. The highest CFU counts observed after $2 \mathrm{~h}, 4 \mathrm{~h}, 6 \mathrm{~h}$, $8 \mathrm{~h}, 10 \mathrm{~h}$ and $12 \mathrm{~h}$ of incubation were 13.36, 13.00, 13.12, 13.71, 14.20 and $15.33 \ln$ units $m \ell^{-1}$ respectively. During Week 5, a gradual increase in the abundance of THAB occurred, which ranged from 9.90 to $12.74 \ln$ units $\mathrm{m}^{\ell^{-1}}$ and was observed during the first 6 hours of incubation (Fig. 2). This phenomenon was also observed during the first $8 \mathrm{~h}$ of incubation in Week 13, and the abundance in THAB varied from 11.51 to $13.71 \mathrm{ln}$ 
Figure 1

Variation in physico-chemical characteristics of water samples over the sampling period

(A: Water column thickness,

B: temperature; C: turbidity;

D: total suspended solids;

E: colour; $\mathbf{F}$ : $p H$; $\mathbf{G}$ : dissolved

$\mathrm{CO}_{2} ; \mathrm{H}$ : electrical conductivity; I: $\mathrm{NH}_{4}^{+}$; and $\mathrm{J}: \mathrm{BOD} 5$
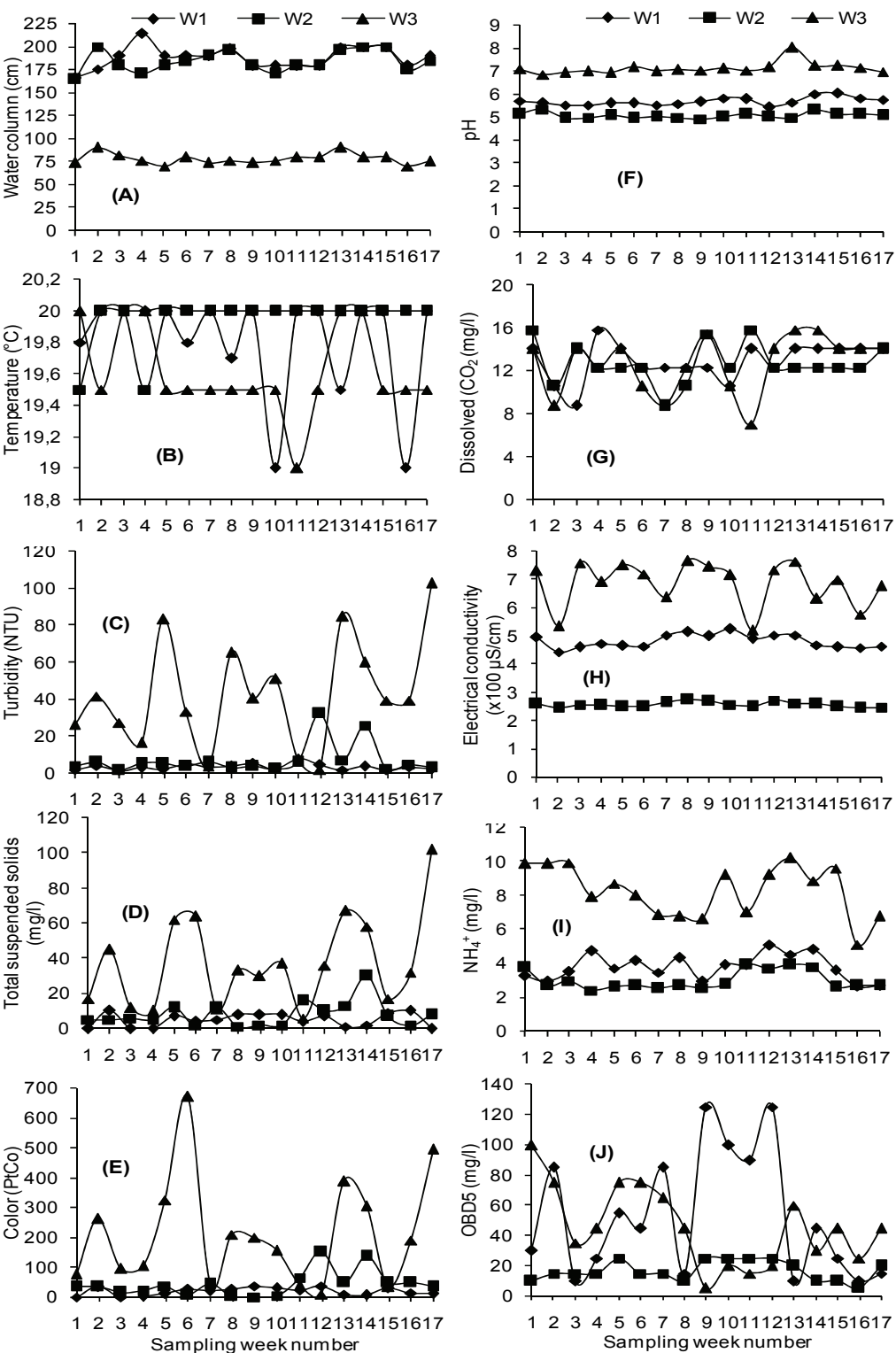

units $\cdot m \ell^{-1}$ (Fig. 2). In some sampling weeks, a decrease in CFU abundance was observed during the first few hours of incubation (Fig. 2). The CFU abundance in Well W1 varied from 9.90 to $13.12 \ln$ units $\cdot \ell^{-1}$ after $6 \mathrm{~h}$ of incubation, and from 10.60 to $15.33 \ln$ units $\cdot \ell^{-1}$ after $12 \mathrm{~h}$ of incubation (Fig. 2).

In Well W2, the THAB abundance ranged from 9.90 to $14.25 \ln$ units $\cdot \ell^{-1}$ (Fig. 2). The highest value of the CFU abundance after $2 \mathrm{~h}, 4 \mathrm{~h}, 6 \mathrm{~h}, 8 \mathrm{~h}$ and $10 \mathrm{~h}$ of incubation was $13.08,13.71,13.49,13.86$ and $14 \ln$ units $\cdot \ell^{-1}$, respectively (Fig. 2). The lowest cell abundance after $6 \mathrm{~h}$ of incubation was 9.90 $\ln$ units. $m \ell^{-1}$. The highest cell abundance recorded after $12 \mathrm{~h}$ of incubation was $14.63 \mathrm{ln}$ units $\mathrm{m} \ell^{-1}$, recorded in Week 2. In this week, the initial CFU abundance was $12.97 \ln$ units $\cdot \mathrm{m}^{-1}$; after $2 \mathrm{~h}, 4 \mathrm{~h}, 6 \mathrm{~h}, 8 \mathrm{~h}$ and $10 \mathrm{~h}$ of incubation, it was 9.90, 11.98, 11.51, 10.60 and $13.4 \ln$ units.m $\ell^{-1}$, respectively (Fig. 2).

In Well W3, initial THAB abundance ranged from 9.90 to $14 \ln$ units $m \ell^{-1}$. During the incubations an increase in abundance occurred in some sampling weeks, as observed in Wells W1 and W2 (Fig. 2). The greatest CFU abundance observed after $2 \mathrm{~h}, 4 \mathrm{~h}, 6 \mathrm{~h}, 8 \mathrm{~h}, 10 \mathrm{~h}$ and $12 \mathrm{~h}$ of incubation was 13.91, 14.39, 14.41, 14.26, 14.93 and $15.88 \mathrm{ln}$ units'm $\ell^{-1}$, respectively (Fig. 2).
During Weeks 13 and 14, a gradual increase was observed in the first 4 hours, from 11.98 to $12.90 \ln$ units.m $\ell^{-1}$ and from 13.77 to $14.39 \ln$ units.m $\ell^{-1}$, respectively (Fig. 2). During Weeks 6 and 7, the CFU abundances at the initial moments were 13.08 and 13.51 $\ln$ units $m \ell^{-1}$, respectively. After $6 \mathrm{~h}$ of incubation, the counts were 14.41 and $12.10 \ln$ units $\cdot m \ell^{-1}$, respectively. The highest CFU abundances were recorded after $12 \mathrm{~h}$. The values were 14.63 and $13.81 \ln$ units $\cdot \ell^{-1}$, respectively (Fig. 2).

\section{Temporal variation in the number of enterobacteria}

Bacteria isolated on MacConkey agar medium (Bio-Rad) and considered as enterobacteria were: straight rods, Gram negative, indole-producing, nitrate-reducing, D-glucose fermenting, oxidase negative and catalase positive. The initial number of enterobacteria in Well W1 fluctuated between 4.09 and 9.59 ln units.m $\ell^{-1}$ (Fig. 3). The highest value of the CFU abundance after $2 \mathrm{~h}, 4 \mathrm{~h}, 6 \mathrm{~h}, 8 \mathrm{~h}, 10 \mathrm{~h}$ and $12 \mathrm{~h}$ of incubation was 7.97, 7.93, 7.91, 8.13, 8.40 and $9.18 \mathrm{ln}$ units $\cdot \mathrm{m}^{-1}$, respectively (Fig. 3). In this well, with the exception of Week 1, a decrease was observed in cell counts of enterobacteria during the first 

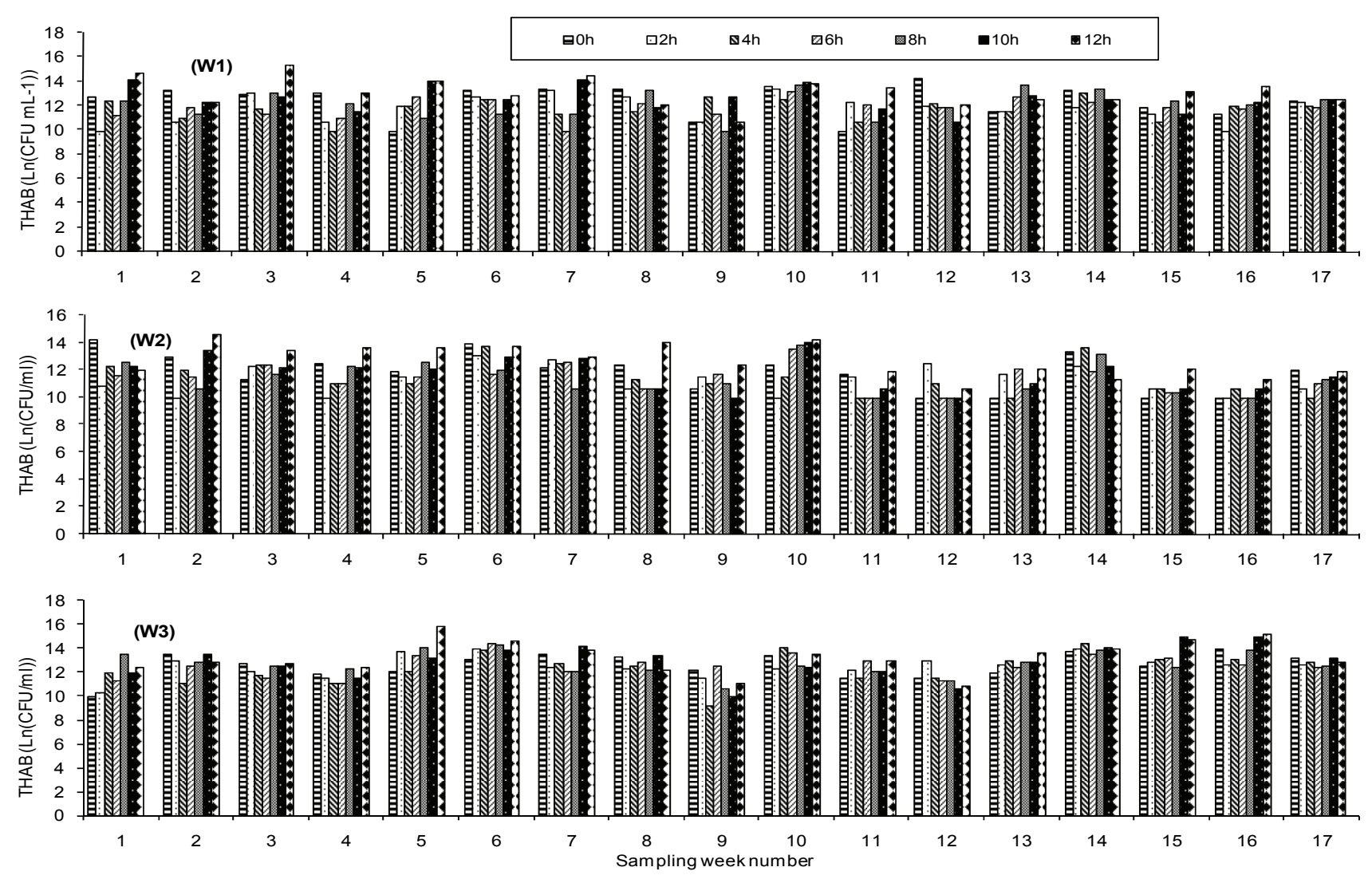

Figure 2

Temporal variation of mean values of the abundance of THAB in samples for each sampling week in Wells W1, W2 and W3, respectively
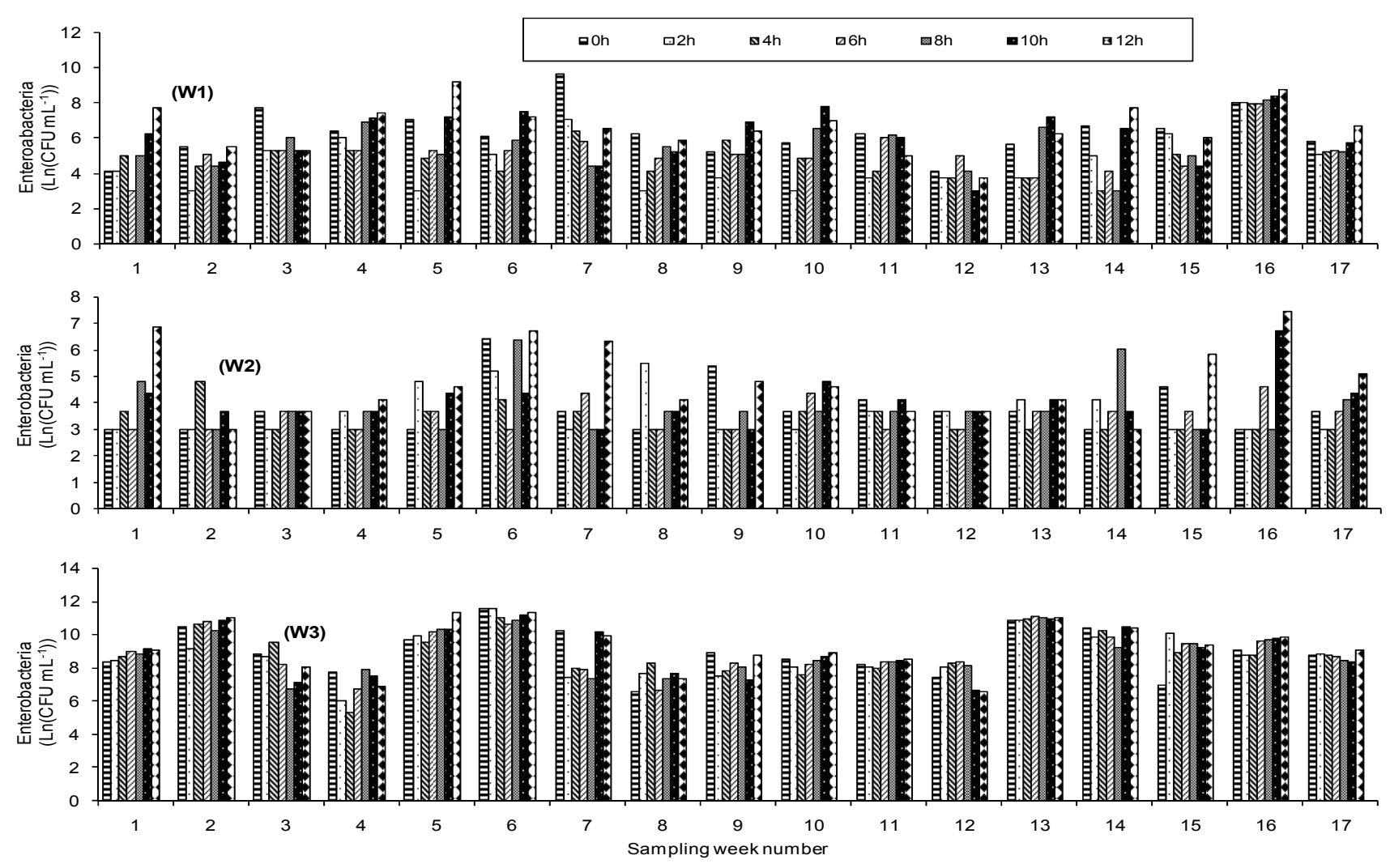

Figure 3

Temporal variation of mean values of enterobacteria abundance in samples for each sampling week in Wells W1, W2 and W3, respectively 


\begin{tabular}{|c|c|c|c|c|c|c|}
\hline \multirow{4}{*}{\begin{tabular}{|l|} 
\\
$\begin{array}{l}\text { Sampling } \\
\text { week }\end{array}$ \\
\end{tabular}} & \multicolumn{5}{|c|}{ 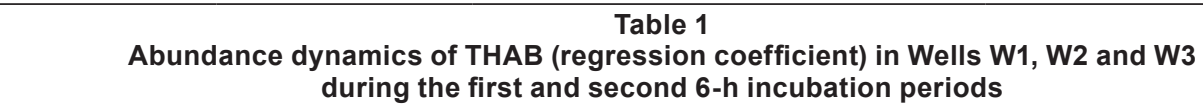 } & \\
\hline & \multicolumn{6}{|c|}{ Cell abundance dynamics $\left(\mathrm{h}^{-1}\right)$ in each well during each considered sequence of the incubation period } \\
\hline & \multicolumn{2}{|c|}{ Well W1 } & \multicolumn{2}{|c|}{ Well W2 } & \multicolumn{2}{|c|}{$\begin{array}{l}\text { Well W3 } \\
\end{array}$} \\
\hline & $6: 00-12: 00$ & 12:00-18:00 & $6: 00-12: 00$ & $12: 00-18: 00$ & $6: 00-12: 00$ & $12: 00-18: 00$ \\
\hline 1 & $\begin{array}{l}-0.102 \\
(0.042)\end{array}$ & $\begin{array}{c}0.622 \\
(0.966)\end{array}$ & $\begin{array}{l}-0.323 \\
(0.321)\end{array}$ & $\begin{array}{c}0.042 \\
(0.073)\end{array}$ & $\begin{array}{c}0.262 \\
(0.638)\end{array}$ & $\begin{array}{c}0.094 \\
(0.066)\end{array}$ \\
\hline 2 & $\begin{array}{l}-0.188 \\
(0.182)\end{array}$ & $\begin{array}{c}0.118 \\
(0.404)\end{array}$ & $\begin{array}{l}-0.115 \\
(0.053)\end{array}$ & $\begin{array}{l}0.607 \\
(0.743)\end{array}$ & $\begin{array}{l}-0.258 \\
(0.377)\end{array}$ & $\begin{array}{c}0.092 \\
(0.307)\end{array}$ \\
\hline 3 & $\begin{array}{l}-0.310 \\
(0.824)\end{array}$ & $\begin{array}{l}0.586 \\
(0.814)\end{array}$ & $\begin{array}{c}0.167 \\
(0.664)\end{array}$ & $\begin{array}{c}0.182 \\
(0.415)\end{array}$ & $\begin{array}{l}-0.195 \\
(0.951)\end{array}$ & $\begin{array}{c}0.179 \\
(0.721)\end{array}$ \\
\hline 4 & $\begin{array}{l}-0.337 \\
(0.423)\end{array}$ & $\begin{array}{c}0.277 \\
(0.631)\end{array}$ & $\begin{array}{l}-0.165 \\
(0.163)\end{array}$ & $\begin{array}{c}0.387 \\
(0.876)\end{array}$ & $\begin{array}{l}-0.153 \\
(0.900)\end{array}$ & $\begin{array}{c}0.169 \\
(0.431)\end{array}$ \\
\hline 5 & $\begin{array}{c}0.425 \\
(0.811)\end{array}$ & $\begin{array}{c}0.339 \\
(0.376)\end{array}$ & $\begin{array}{l}-0.076 \\
(0.315)\end{array}$ & $\begin{array}{c}0.297 \\
(0.727)\end{array}$ & $\begin{array}{c}0.106 \\
(0.109)\end{array}$ & $\begin{array}{c}0.339 \\
(0.493)\end{array}$ \\
\hline 6 & $\begin{array}{l}-0.129 \\
(0.841)\end{array}$ & $\begin{array}{c}0.111 \\
(0.184)\end{array}$ & $\begin{array}{l}-0.306 \\
(0.612)\end{array}$ & $\begin{array}{c}0.355 \\
(0.960)\end{array}$ & $\begin{array}{c}0.197 \\
(0.855)\end{array}$ & $\begin{array}{c}0.010 \\
(0.005)\end{array}$ \\
\hline 7 & $\begin{array}{c}-0.615 \\
(0.904)\end{array}$ & $\begin{array}{c}0.822 \\
(0.928)\end{array}$ & $\begin{array}{c}0.039 \\
(0.210) \\
\end{array}$ & $\begin{array}{c}0.166 \\
(0.153)\end{array}$ & $\begin{array}{c}-0.195 \\
(0.676)\end{array}$ & $\begin{array}{c}0.363 \\
(0.702)\end{array}$ \\
\hline 8 & $\begin{array}{l}-0.228 \\
(0.585)\end{array}$ & $\begin{array}{l}-0.089 \\
(0.126)\end{array}$ & $\begin{array}{l}-0.234 \\
(0.510)\end{array}$ & $\begin{array}{c}0.512 \\
(0.600)\end{array}$ & $\begin{array}{l}-0.054 \\
(0.123)\end{array}$ & $\begin{array}{l}-0.023 \\
(0.016)\end{array}$ \\
\hline 9 & $\begin{array}{c}0.208 \\
(0.300)\end{array}$ & $\begin{array}{c}0.035 \\
(0.005)\end{array}$ & $\begin{array}{c}0.139 \\
(0.519)\end{array}$ & $\begin{array}{c}0.049 \\
(0.014)\end{array}$ & $\begin{array}{l}-0.070 \\
(0.014)\end{array}$ & $\begin{array}{l}-0.260 \\
(0.372)\end{array}$ \\
\hline 10 & $\begin{array}{l}-0.116 \\
(0.375)\end{array}$ & $\begin{array}{c}0.104 \\
(0.612)\end{array}$ & $\begin{array}{c}0.245 \\
(0.175)\end{array}$ & $\begin{array}{c}0.117 \\
(0.959)\end{array}$ & $\begin{array}{c}0.124 \\
(0.182)\end{array}$ & $\begin{array}{l}-0.027 \\
(0.011)\end{array}$ \\
\hline 11 & $\begin{array}{c}0.244 \\
(0.293)\end{array}$ & $\begin{array}{c}0.267 \\
(0.326)\end{array}$ & $\begin{array}{l}-0.349 \\
(0.838)\end{array}$ & $\begin{array}{c}0.327 \\
(0.844)\end{array}$ & $\begin{array}{c}0.023 \\
(0.032) \\
\end{array}$ & $\begin{array}{c}0.150 \\
(0.763)\end{array}$ \\
\hline 12 & $\begin{array}{c}-0.342 \\
(0.638)\end{array}$ & $\begin{array}{l}-0.025 \\
(0.009)\end{array}$ & $\begin{array}{l}-0.073 \\
(0.024)\end{array}$ & $\begin{array}{c}0.104 \\
(0.600)\end{array}$ & $\begin{array}{l}-0.105 \\
(0.127)\end{array}$ & $\begin{array}{l}-0.106 \\
(0.609)\end{array}$ \\
\hline 13 & $\begin{array}{c}0.184 \\
(0.600)\end{array}$ & $\begin{array}{l}-0.075 \\
(0.138)\end{array}$ & $\begin{array}{c}0.240 \\
(0.283) \\
\end{array}$ & $\begin{array}{c}0.020 \\
(0.004)\end{array}$ & $\begin{array}{c}0.075 \\
(0.252) \\
\end{array}$ & $\begin{array}{c}0.181 \\
(0.854)\end{array}$ \\
\hline 14 & $\begin{array}{l}-0.088 \\
(0.123)\end{array}$ & $\begin{array}{c}-0.015 \\
(0.006)\end{array}$ & $\begin{array}{c}-0.153 \\
(0.224)\end{array}$ & $\begin{array}{l}-0.125 \\
(0.173)\end{array}$ & $\begin{array}{c}-0.015 \\
(0.011)\end{array}$ & $\begin{array}{c}0.081 \\
(0.695)\end{array}$ \\
\hline 15 & $\begin{array}{l}-0.035 \\
(0.022)\end{array}$ & $\begin{array}{c}0.142 \\
(0.211)\end{array}$ & $\begin{array}{c}0.106 \\
(0.229)\end{array}$ & $\begin{array}{c}0.283 \\
(0.724)\end{array}$ & $\begin{array}{c}0.099 \\
(0.914)\end{array}$ & $\begin{array}{c}0.365 \\
(0.584)\end{array}$ \\
\hline 16 & $\begin{array}{c}0.165 \\
(0.213)\end{array}$ & $\begin{array}{c}0.291 \\
(0.864)\end{array}$ & $\begin{array}{c}0.035 \\
(0.066)\end{array}$ & $\begin{array}{c}0.243 \\
(0.890)\end{array}$ & $\begin{array}{l}-0.184 \\
(0.531)\end{array}$ & $\begin{array}{c}0.439 \\
(0.939)\end{array}$ \\
\hline 17 & $\begin{array}{l}-0.097 \\
(0.953)\end{array}$ & $\begin{array}{c}0.089 \\
(0.505)\end{array}$ & $\begin{array}{c}-0.182 \\
(0.291)\end{array}$ & $\begin{array}{c}0.138 \\
(0.994)\end{array}$ & $\begin{array}{c}-0.104 \\
(0.659) \\
\end{array}$ & $\begin{array}{c}0.099 \\
(0.567)\end{array}$ \\
\hline
\end{tabular}

hours of incubation. This decrease was followed by a stationary phase, after which an increase in the number of cells was observed. During some sampling weeks, the number of cells remained unchanged for 4 or 6 hours of incubation. This was observed in Weeks 3, 9 and 11 (Fig. 3). In Weeks 3, 7, 8, 11 and 12 , the number of cells of enterobacteria recorded after $12 \mathrm{~h}$ of incubation was lower than that recorded in the initial stages of the study (Fig. 3). The highest value ( $9.18 \ln$ units $\cdot \mathrm{m}^{-1}$ ) recorded after $12 \mathrm{~h}$ of incubation was in Week 5. In this week, the CFU abundance was initially $7.04 \mathrm{ln}$ units $\cdot \mathrm{m}^{-1}$ and dropped to $5.30 \mathrm{ln}$ units $\cdot \mathrm{m}^{-1}$ after $6 \mathrm{~h}$ of incubation (Fig. 3).

In Well W2, the number of enterobacteria fluctuated between 3.00 and $6.40 \mathrm{ln}$ units $\cdot \ell^{-1}$, and decreased during the first hours of incubation. In some sampling weeks, cell numbers remained unchanged for 4 or $6 \mathrm{~h}$ of incubation. The highest cell numbers observed after $2 \mathrm{~h}$ and $4 \mathrm{~h}$ were 5.48 and 4.79 $\ln$ units $\cdot \mathrm{m}^{-1}$, respectively. After $6 \mathrm{~h}$ of incubation, the number of enterobacteria ranged between 3 and $4.61 \mathrm{ln}$ units. $\mathrm{m}^{-1}$ (Fig.
3). The highest number of enterobacteria was observed after $12 \mathrm{~h}$ of incubation and was $7.44 \mathrm{ln}$ units $\mathrm{m}^{-1}$, recorded in Week 16. During this week the initial concentration was $3 \mathrm{ln}$ units· $m \ell^{-1}$, and increased to $4.61 \ln$ units $m \ell^{-1}$ after $6 \mathrm{~h}$ (Fig. 3).

In Well W3, the initial cell concentration ranged between 6.55 and $11.51 \ln$ units $\cdot \ell^{-1}$, and observed temporal variations in CFU abundance were also similar to those of other sampling sites (Fig. 3). The highest values of cell abundance observed after $2 \mathrm{~h}, 4 \mathrm{~h}, 6 \mathrm{~h}, 8 \mathrm{~h}, 10 \mathrm{~h}$ and $12 \mathrm{~h}$ of incubation were 11.51, $11.00,11.07,11.00,11.16$ and $11.29 \ln$ units. $\ell^{-1}$, respectively. As noted for other sampling sites, cell abundance sometimes remained unchanged during the first $4 \mathrm{~h}$ of incubation (Fig. 3).

\section{Cell abundance dynamics and relation to physico- chemical parameters}

The cell abundance dynamics was assessed during each of the two parts of the incubation period considered (from Time 


\begin{tabular}{|c|c|c|c|c|c|c|}
\hline \multicolumn{7}{|c|}{$\begin{array}{c}\text { Table } 2 \\
\begin{array}{c}\text { Abundance dynamics of enterobacteria (regression coefficient) in Wells W1, W2 and W3 } \\
\text { during the first and second 6-h incubation periods }\end{array}\end{array}$} \\
\hline \multirow{3}{*}{$\begin{array}{l}\text { Sampling } \\
\text { week } n^{\circ}\end{array}$} & \multicolumn{6}{|c|}{ Cell abundance dynamic $\left(h^{-1}\right)$ in each well during each considered sequence of the incubation period. } \\
\hline & \multicolumn{2}{|c|}{ Well W1 } & \multicolumn{2}{|c|}{ Well W2 } & \multicolumn{2}{|c|}{ Well W3 } \\
\hline & $6: 00-12: 00$ & $12: 00-18: 00$ & $6: 00-12: 00$ & $12: 00-18: 00$ & $6: 00-12: 00$ & $12: 00-18: 00$ \\
\hline 1 & $\begin{array}{l}-0.122 \\
(0.157)\end{array}$ & $\begin{array}{c}0.771 \\
(0.992) \\
\end{array}$ & $\begin{array}{c}0.035 \\
(0.066)\end{array}$ & $\begin{array}{c}0.560 \\
(0.816)\end{array}$ & $\begin{array}{c}0.097 \\
(0.883)\end{array}$ & $\begin{array}{c}0.036 \\
(0.377)\end{array}$ \\
\hline 2 & $\begin{array}{c}0.009 \\
(0.000) \\
\end{array}$ & $\begin{array}{c}0.072 \\
(0.143) \\
\end{array}$ & $\begin{array}{c}0.089 \\
(0.066) \\
\end{array}$ & $\begin{array}{c}0.035 \\
(0.066) \\
\end{array}$ & $\begin{array}{c}0.160 \\
(0.202) \\
\end{array}$ & $\begin{array}{c}0.058 \\
(0.208) \\
\end{array}$ \\
\hline 3 & $\begin{array}{l}-0.359 \\
(0.600)\end{array}$ & $\begin{array}{c}-0.035 \\
(0.066) \\
\end{array}$ & $\begin{array}{c}0.001 \\
(0.000)\end{array}$ & $\begin{array}{c}0.000 \\
(0.000)\end{array}$ & $\begin{array}{l}-0.058 \\
(0.073) \\
\end{array}$ & $\begin{array}{l}-0.007 \\
(0.000)\end{array}$ \\
\hline 4 & $\begin{array}{l}-0.199 \\
(0.899) \\
\end{array}$ & $\begin{array}{c}0.321 \\
(0.788)\end{array}$ & $\begin{array}{l}-0.035 \\
(0.066) \\
\end{array}$ & $\begin{array}{c}0.165 \\
(0.870) \\
\end{array}$ & $\begin{array}{l}-0.186 \\
(0.221) \\
\end{array}$ & $\begin{array}{c}0.015 \\
(0.005) \\
\end{array}$ \\
\hline 5 & $\begin{array}{l}-0.172 \\
(0.070)\end{array}$ & $\begin{array}{c}0.686 \\
(0.859)\end{array}$ & $\begin{array}{c}0.049 \\
(0.029)\end{array}$ & $\begin{array}{c}0.207 \\
(0.537)\end{array}$ & $\begin{array}{l}0.041 \\
(0.167\end{array}$ & $\begin{array}{c}0.178 \\
(0.729)\end{array}$ \\
\hline 6 & $\begin{array}{l}-0.167 \\
(0.277)\end{array}$ & $\begin{array}{c}0.365 \\
(0.812)\end{array}$ & $\begin{array}{l}-0.565 \\
(0.999)\end{array}$ & $\begin{array}{c}0.458 \\
(0.459)\end{array}$ & $\begin{array}{l}-0.156 \\
(0.899)\end{array}$ & $\begin{array}{c}0.114 \\
(0.973)\end{array}$ \\
\hline 7 & $\begin{array}{l}-0.604 \\
(0.866)\end{array}$ & $\begin{array}{c}0.109 \\
(0.071)\end{array}$ & $\begin{array}{c}0.139 \\
(0.400)\end{array}$ & $\begin{array}{c}0.292 \\
(0.228)\end{array}$ & $\begin{array}{l}-0.326 \\
(0.443)\end{array}$ & $\begin{array}{c}0.444 \\
(0.646)\end{array}$ \\
\hline 8 & $\begin{array}{l}-0.159 \\
(0.093)\end{array}$ & $\begin{array}{c}0.150 \\
(0.701)\end{array}$ & $\begin{array}{l}-0.124 \\
(0.666)\end{array}$ & $\begin{array}{c}0.165 \\
(0.870)\end{array}$ & $\begin{array}{c}0.046 \\
(0.019)\end{array}$ & $\begin{array}{c}0.116 \\
(0.479)\end{array}$ \\
\hline 9 & $\begin{array}{c}0.092 \\
(0.066)\end{array}$ & $\begin{array}{c}0.289 \\
(0.642) \\
\end{array}$ & $\begin{array}{l}-0.359 \\
(0.600)\end{array}$ & $\begin{array}{c}0.234 \\
(0.510)\end{array}$ & $\begin{array}{l}-0.082 \\
(0.121)\end{array}$ & $\begin{array}{c}0.032 \\
(0.017)\end{array}$ \\
\hline 10 & $\begin{array}{l}-0.047 \\
(0.011)\end{array}$ & $\begin{array}{c}0.382 \\
(0.617)\end{array}$ & $\begin{array}{c}0.139 \\
(0.400)\end{array}$ & $\begin{array}{c}0.088 \\
(0.225) \\
\end{array}$ & $\begin{array}{l}-0.069 \\
(0.241) \\
\end{array}$ & $\begin{array}{c}0.119 \\
(0.997) \\
\end{array}$ \\
\hline 11 & $\begin{array}{l}-0.019 \\
(0.001)\end{array}$ & $\begin{array}{l}-0.167 \\
(0.586)\end{array}$ & $\begin{array}{l}-0.165 \\
(0.870)\end{array}$ & $\begin{array}{c}0.124 \\
(0.494)\end{array}$ & $\begin{array}{c}0.020 \\
(0.104)\end{array}$ & $\begin{array}{c}0.031 \\
(0.951)\end{array}$ \\
\hline 12 & $\begin{array}{c}0.127 \\
(0.308) \\
\end{array}$ & $\begin{array}{l}-0.243 \\
(0.595) \\
\end{array}$ & $\begin{array}{l}-0.139 \\
(0.800) \\
\end{array}$ & $\begin{array}{c}0.104 \\
(0.600) \\
\end{array}$ & $\begin{array}{c}0.144 \\
(0.836) \\
\end{array}$ & $\begin{array}{l}-0.338 \\
(0.871) \\
\end{array}$ \\
\hline 13 & $\begin{array}{l}-0.292 \\
(0.600) \\
\end{array}$ & $\begin{array}{c}0.414 \\
(0.477) \\
\end{array}$ & $\begin{array}{c}-0.055 \\
(0.096) \\
\end{array}$ & $\begin{array}{c}0.081 \\
(0.800) \\
\end{array}$ & $\begin{array}{c}0.033 \\
(0.624) \\
\end{array}$ & $\begin{array}{l}-0.015 \\
(0.279) \\
\end{array}$ \\
\hline 14 & $\begin{array}{l}-0.486 \\
(0.649)\end{array}$ & $\begin{array}{c}0.709 \\
(0.732)\end{array}$ & $\begin{array}{c}0.049 \\
(0.054)\end{array}$ & $\begin{array}{l}-0.222 \\
(0.184)\end{array}$ & $\begin{array}{l}-0.062 \\
(0.326)\end{array}$ & $\begin{array}{c}0.153 \\
(0.453)\end{array}$ \\
\hline 15 & $\begin{array}{l}-0.375 \\
(0.948) \\
\end{array}$ & $\begin{array}{c}0.217 \\
(0.529)\end{array}$ & $\begin{array}{l}-0.137 \\
(0.216)\end{array}$ & $\begin{array}{c}0.321 \\
(0.381) \\
\end{array}$ & $\begin{array}{c}0.315 \\
(0.356) \\
\end{array}$ & $\begin{array}{l}-0.022 \\
(0.214)\end{array}$ \\
\hline 16 & $\begin{array}{l}-0.015 \\
(0.986) \\
\end{array}$ & $\begin{array}{c}0.135 \\
(0.988) \\
\end{array}$ & $\begin{array}{c}0.241 \\
(0.600) \\
\end{array}$ & $\begin{array}{c}0.610 \\
(0.607) \\
\end{array}$ & $\begin{array}{c}0.084 \\
(0.265) \\
\end{array}$ & $\begin{array}{c}0.029 \\
(0.940) \\
\end{array}$ \\
\hline 17 & $\begin{array}{l}-0.065 \\
(0.301)\end{array}$ & $\begin{array}{c}0.226 \\
(0.790)\end{array}$ & $\begin{array}{c}0.001 \\
(0.000)\end{array}$ & $\begin{array}{c}0.222 \\
(0.966)\end{array}$ & $\begin{array}{l}-0.017 \\
(0.676)\end{array}$ & $\begin{array}{c}0.058 \\
(0.211)\end{array}$ \\
\hline
\end{tabular}

zero $\left(\mathrm{T}_{0}\right)$ to the $6^{\text {th }}$ hour, and from the $6^{\text {th }}$ hour to the $12^{\text {th }}$ hour). It appeared that a decrease in the concentration of cultivable THAB and enterobacteria occurred in most cases during the first $6 \mathrm{~h}$ of incubation (Tables 1-2). The CAIR of the THAB during this incubation period ranged between $0.035 \mathrm{~h}^{-1}$ (Week 15 ) and $0.615 \mathrm{~h}^{-1}$ (Week 7) in Well W1, between $0.073 \mathrm{~h}^{-1}$ (Week 12) and $0.349 \mathrm{~h}^{-1}$ (Week 11) in Well W2, and between $0.015 \mathrm{~h}^{-1}$ (Week 14) and $0.258 \mathrm{~h}^{-1}$ (Week 2) in Well W3 (Table 1). During this period, the highest CAGR for THAB was $0.425 \mathrm{~h}^{-1}$ in Well W1 (Week 5), $0.245 \mathrm{~h}^{-1}$ in Well W2 (Week 10), and $0.262 \mathrm{~h}^{-1}$ in Well W3 (Week 1) (Table 1). During the second incubation period (from the $6^{\text {th }}$ to the $12^{\text {th }}$ hour), the abundance dynamics of the THAB were positive in most cases. The CAGR ranged between $0.035 \mathrm{~h}^{-1}$ (Week 9) and $0.822 \mathrm{~h}^{-1}$ (Week 7) in Well W1, between $0.020 \mathrm{~h}^{-1}$ (Week 13) and $0.607 \mathrm{~h}^{-1}$ (Week 2) in Well $\mathrm{W} 2$, and between $0.010 \mathrm{~h}^{-1}$ (Week 6) and $0.439 \mathrm{~h}^{-1}$ (Week 16) in Well W3 (Table 1). It was noted that the highest CAGRs of the THAB registered during this period were preceded by negative values of cell abundance dynamics recorded during the first period (Table 1). The highest CAIRs during the second period were $0.075 \mathrm{~h}^{-1}$ in Well W1 (Week 13), $0.125 \mathrm{~h}^{-1}$ in Well W2 (Week 14) and $0.260 \mathrm{~h}^{-1}$ in Well W3 (Week 9) (Table 1).

In Weeks 8, 12 and 14 in Well W1, the cell dynamics of the THAB were negative during the two incubation periods (Table 1). The CAIRs during the first and second period were $0.228 \mathrm{~h}^{-1}$ and $0.089 \mathrm{~h}^{-1}$, respectively, for Week $8,0.342 \mathrm{~h}^{-1}$ and $0.025 \mathrm{~h}^{-1}$, respectively, for Week 12, and $0.088 \mathrm{~h}^{-1}$ and $0.015 \mathrm{~h}^{-1}$, respectively, for Week 14 (Table 1). In Well W2, the CAIR decreased in Week 14 from $0.153 \mathrm{~h}^{-1}$ in the first incubation period to $0.125 \mathrm{~h}^{-1}$ in the second. The same observation was made in Well W3 in which the CAIR value decreased in Week 8 from $0.054 \mathrm{~h}^{-1}$ to $0.023 \mathrm{~h}^{-1}$. However, in the same well in Week 9, an increase in CAIR from $0.070 \mathrm{~h}^{-1}$ to $0.260 \mathrm{~h}^{-1}$ was observed (Table 1). Between Weeks 8 and 9 , no change in climate and temperature was observed, though a mild rain fell in the region 2 days before Week 9.

The CAIR value for the enterobacteria in the first incubation period (6:00-12:00) ranged between $0.015 \mathrm{~h}^{-1}$ (Week 16) and $0.604 \mathrm{~h}^{-1}$ (Week 7) in W1, between $0.035 \mathrm{~h}^{-1}$ (Week 4) and $0.565 \mathrm{~h}^{-1}$ (Week 6) in W2, and between $0.017 \mathrm{~h}^{-1}$ (Week 17) and $0.326 \mathrm{~h}^{-1}$ (Week 7) in W3 (Table 2). During this period, the 
Table 3

Correlation coefficients between physico-chemical parameters and cell abundance dynamics in Wells W1, W2 and W3 during the first and second 6-h incubation periods

\begin{tabular}{|c|c|c|c|c|c|c|c|c|c|c|c|c|}
\hline \multirow{4}{*}{$\begin{array}{l}\text { Physico- } \\
\text { chemical } \\
\text { parameters }\end{array}$} & \multicolumn{12}{|c|}{ Correlation coefficient } \\
\hline & \multicolumn{4}{|c|}{ Well W1 } & \multicolumn{4}{|c|}{ Well W2 } & \multicolumn{4}{|c|}{ Well W3 } \\
\hline & \multicolumn{2}{|c|}{$6: 00-12: 00$} & \multicolumn{2}{|c|}{$12: 00-18: 00$} & \multicolumn{2}{|c|}{$6: 00-12: 00$} & \multicolumn{2}{|c|}{$12: 00-18: 00$} & \multicolumn{2}{|c|}{$6: 00-12: 00$} & \multicolumn{2}{|c|}{$12: 00-18: 00$} \\
\hline & THAB & $\begin{array}{l}\text { Entero- } \\
\text { bacteria }\end{array}$ & THAB & $\begin{array}{l}\text { Entero- } \\
\text { bacteria }\end{array}$ & THAB & $\begin{array}{l}\text { Entero- } \\
\text { bacteria }\end{array}$ & THAB & $\begin{array}{l}\text { Entero- } \\
\text { bacteria }\end{array}$ & THAB & $\begin{array}{l}\text { Entero- } \\
\text { bacteria }\end{array}$ & THAB & $\begin{array}{l}\text { Entero- } \\
\text { bacteria }\end{array}$ \\
\hline Temperature & 0.293 & 0.331 & 0.117 & 0.001 & -0.274 & 0.268 & 0.041 & -0.289 & 0.229 & -0.036 & -0.123 & -0.202 \\
\hline Conductivity & 0.177 & 0.012 & -0.019 & 0.096 & 0.067 & 0.022 & -0.321 & -0.239 & -0.091 & 0.112 & -0.152 & 0.021 \\
\hline BOD5 & 0.281 & -0.189 & -0.152 & -0.064 & 0.127 & 0.037 & -0.255 & $-0.555 * *$ & $0.616 * * *$ & 0.231 & -0.077 & 0.068 \\
\hline $\mathrm{pH}$ & $-0.713^{*} * *$ & 0.040 & -0.318 & 0.251 & -0.162 & -0.291 & 0.306 & $\begin{array}{l}0.060 \\
\end{array}$ & -0.297 & -0.098 & 0.004 & -0.127 \\
\hline TSS & -0.007 & -0.290 & -0.288 & -0.313 & -0.055 & -0.356 & -0.252 & -0.202 & -0.182 & 0.018 & -0.276 & -0.027 \\
\hline Colour & -0.049 & -0.299 & $-0.482 *$ & -0.391 & -0.279 & -0.243 & -0.264 & -0.080 & -0.014 & -0.330 & -0.324 & -0.170 \\
\hline Turbidity & 0.047 & -0.336 & -0.267 & -0.229 & -0.262 & -0.107 & -0.248 & -0.157 & -0.306 & -0.521 & -0.100 & -0.296 \\
\hline $\mathrm{CO}_{2}$ & -0.110 & 0.001 & -0.110 & $0.441^{*}$ & $0.517 * *$ & 0.013 & $-0.414 *$ & 0.120 & -0.237 & -0.260 & 0.172 & -0.226 \\
\hline Water column & 0.110 & $0.513 * *$ & -0.182 & -0.031 & -0.227 & -0.041 & 0.310 & -0.291 & 0.018 & 0.018 & -0.379 & -0.204 \\
\hline $\mathrm{NH}_{4}^{+}$ & 0.128 & 0.309 & -0.296 & 0.273 & $0.423^{*}$ & -0.236 & $-0.432 *$ & -0.102 & 0.196 & 0.068 & -0.319 & -0.097 \\
\hline
\end{tabular}

Enterobact.: Enterobacteria; THAB: total heterotrophic aerobe bacteria; Temperat.: temperature; Elec. Cond.: electrical conductivity;

Water Col.: water column thickness

$n=17 ; * P<0.1 ; * * P<0.05 ; * * * P<0.01$

highest CAGR noted was $0.127 \mathrm{~h}^{-1}$ in $\mathrm{W} 1,0.241 \mathrm{~h}^{-1}$ in $\mathrm{W} 2$, and $0.315 \mathrm{~h}^{-1}$ in W3. The CAGR ranged between $0.072 \mathrm{~h}^{-1}$ (Week 2) and $0.771 \mathrm{~h}^{-1}$ (Week 1) in W1, between $0.035 \mathrm{~h}^{-1}$ (Week 2) and $0.610 \mathrm{~h}^{-1}$ (Week 16) in W2, and between $0.015 \mathrm{~h}^{-1}$ (Week 4) and $0.444 \mathrm{~h}^{-1}$ (Week 7) in W3 (Table 2). As in the case of the THAB, the abundance dynamics of the enterobacteria were found to be positive in most cases during the second incubation period (12:00-18:00)

A Spearman correlation test was performed between the cell abundance dynamics and physico-chemical parameters recorded before incubation. Results revealed that BOD5 was significantly correlated $(P<0.05)$ with abundance dynamics for enterobacteria in $\mathrm{W} 2$, during the incubation period from 6:00 to 12:00 hour, and with the abundance dynamics of THAB in W3 over the same period $(P<0.01)$ (Table 3 ). In $W 1$, the cell abundance dynamics of THAB was correlated $(P<0.01)$ with $\mathrm{pH}$ during the first $6 \mathrm{~h}$ of incubation, and with water colour $(P<0.1)$ during the second incubation period (Table 3$)$. The variation of the water column thickness was correlated with the abundance dynamics of enterobacteria $(P<0.01)$ during the first $6 \mathrm{~h}$ of incubation. $\mathrm{CO}_{2}$ was correlated $(P<0.1)$ with the abundance dynamics of enterobacteria and THAB in W1 and W2 (Table 3). In W2, the increase in $\mathrm{CO}_{2}$ concentration and $\mathrm{NH}_{4}^{+}$ may have resulted in cell growth during the first incubation period and cell inhibition during the second period (Table 3).

\section{Discussion}

This study showed that the abundance of enterobacteria and other heterotrophic aerobic bacteria in groundwater fluctuated during the day. Such changes could result in a decrease or increase in cell abundance. The hourly rates of change in cell numbers over the study period varied between 0.015 to 0.615 $\mathrm{h}^{-1}$ for THAB and between 0.007 to $0.607 \mathrm{~h}^{-1}$ for enterobacteria (Tables 1 and 2). The inhibition rate observed would be related to the starvation response of the cells due to the difficulty in degrading the organic matter present, or due to their growth (Mailloux and Fuller 2003). It has previously been reported that groundwater also harbours stygobiontic fauna of various taxa, and protozoa (Fusconi and Godinho, 1999; Zébazé Togouet et al., 2009). The literature has indicated that selective and non-selective grazing of groundwater bacteria by nanoflagellates can occur during incubation, and that uptake rate depends on the concentration of bacteria and predators (Kinner et al., 1998). Bengtsson (1989) noted that groundwater bacteria from an oligotrophic environment showed a mixed strategy of economised metabolism.

The CAGR values varied from 0.010 to $0.822 \mathrm{~h}^{-1}$ for THAB, and from 0.001 to $0.771 \mathrm{~h}^{-1}$ for enterobacteria (Tables 1 and 2). Harvey and George (1987) studied wells where the temperature ranged between 11 and $14^{\circ} \mathrm{C}$, and detected bacterial growth rates ranging from 0.005 to $0.042 \mathrm{~h}^{-1}$; the highest growth rate was recorded in wells with higher temperature. Mailloux and Fuller (2003) have recorded that in some underground waters the generation time of Comamonas sp. and Acidovorax sp. ranges between 3.90 and $5.08 \mathrm{~h}$, and between 5.53 and 6.97 $\mathrm{h}$, respectively. This corresponds to a growth rate ranging between 0.197 and $0.256 \mathrm{~h}^{-1}$ for Comamonas sp and between 0.143 and $0.181 \mathrm{~h}^{-1}$ for Acidovorax sp. These authors reported that the groundwater sampled was relatively poor in biodegradable organic matter (less than $50 \mathrm{mg} \cdot \ell^{-1}$ ). In this study, the BOD5 values ranged between 5 and $125 \mathrm{mg} \cdot \ell^{-1}$ (Fig. 1). The differences among wells in the concentration of BOD5 are the likely origin of the relative differences noted in CAGR or CAIR values.

In most cases, there was a relative decrease in cell numbers during the first 6 hours of incubation (Figs. 2-3). This behaviour is similar to that reported in previous studies of the introduction and dynamics of bacteria in groundwater. Van Elsas and Heijnen (1990) and Alden and co-workers (2001) indicated that the introduction of bacteria in soil is usually followed by an initial decrease in biomass of the introduced cells, due to environmental influences on cell survival and the stability of abiotic factors such as texture and soil particle size, and dynamic abiotic factors such as temperature, water content, $\mathrm{pH}$, nutrients and other chemicals. The slight decrease in the abundance of enterobacteria and other heterotrophic bacteria during the first hours of incubation could be due to their adaptation to the new environmental conditions.

Abundance dynamics of bacteria in water environments could also be impacted by viral activity (Yates et al., 1990). Pachepsky et al. (2006) indicated that bacterial metabolism is 
relatively inhibited during the adaptation step and this is followed by re-growth. The slight decrease during the first hours of incubation could also be attributed to interaction amongst cells. According to Fallon and Perri (1996), one of the important criteria which influence the survival of the organisms in groundwater is their ability to compete for substrate and nutrients.

Temporal changes in cell abundance were in some cases significantly correlated with initial physico-chemical characteristics of the water, such as $\mathrm{pH}$, colour, BOD5, dissolved $\mathrm{CO}_{2}$ and $\mathrm{NH}_{4}^{+}$(Table 3). The most favourable $\mathrm{pH}$ range for enterobacterial survival in groundwater is 6-7 (Reddy et al., 1981). In addition, the $\mathrm{pH}$ of the environment affects the solubility of compounds and the charge distribution in the system (Fallon and Perri, 1996). In this study, the $\mathrm{pH}$ values ranged between 5.45 and 6.04 in W1, between 4.93 and 5.35 in W2, and between 6.87 and 8.04 in W3 (Fig. 1). The enterobacteria found in these wells have most likely adapted to survive in these different environmental conditions.

Mouser et al. (2009) assessed the influence of ammonium on bacterial community structure and the physiological status of contaminated groundwater. Analysis of the $16 \mathrm{~S}$ subunit of rRNA gene sequences suggested that ammonium may be one of the important factors influencing community composition. In addition, it is the primary source of nitrogen during some geochemical reduction reactions in groundwater systems. The colour of the water is related to the dissolution of metals, which often acts selectively on the evolution of microbial populations in ground water (Benyehuda et al., 2003).

The water temperature in this study ranged between 19 and $20^{\circ} \mathrm{C}$ (Fig. 1). No significant influence of this factor on the changes in CFU abundance was noted (Table 3). However, studies of temporal changes in groundwater quality when stored at different household conditions have noted that the highest CAGR of the THAB at Day 3 of storage was $0.249 \mathrm{~d}^{-1}$ at $3^{\circ} \mathrm{C}, 0.559 \mathrm{~d}^{-1}$ at $10^{\circ} \mathrm{C}, 0.924 \mathrm{~d}^{-1}$ at $18^{\circ} \mathrm{C}$, and $1.233 \mathrm{~d}^{-1}$ at $25^{\circ} \mathrm{C}$; however, at Day 7 of storage, it was $0.362 \mathrm{~d}^{-1}$ at $3^{\circ} \mathrm{C}, 0.497 \mathrm{~d}^{-1}$ at $10^{\circ} \mathrm{C}, 0.690 \mathrm{~d}^{-1}$ at $18^{\circ} \mathrm{C}$, and $0.672 \mathrm{~d}^{-1}$ at $25^{\circ} \mathrm{C}$ (Nola et al., 2010). The absence of a significant correlation with temperature might be due to the incubation duration, which was relatively shorter in the current study.

Bacterial abundance underwent temporal variation. The stabilisation of cell abundance for several hours which was sometimes observed during incubation could be related either to the depletion of available energy sources, or to the effect of certain products synthesised by a small proportion of microorganisms, which in turn act on the majority of cells by inhibiting their metabolism or by lengthening their lag time ( $\mathrm{Li}$ et al., 2006). The impact of the water column thickness on the bacterial abundance fluctuations might be due to a hydrological process in the groundwater environment, and this could affect the chemical composition of the water.

In the aquatic environment in general, multiple microorganisms coexist as communities competing for resources. Attributes such as growth rate and production of quorumsensing inhibitors may allow bacteria to effectively interact and coexist in a water environment (Kolter and Losick, 1998). Simoes et al. (2007) studied the interactions amongst most species of Methylobacterium, Sphingomonas, Burkholderia, Staphylococcus and Acinetobacter genera and noted synergy/ cooperation between some species, and antagonism and neutral interaction between others. In addition, chemical elements have a major influence on micro-organism survival in the aquatic medium. In return, micro-organisms influence water physicochemical properties through release of diverse metabolic wastes, in response to variation of environmental conditions (Tiago et al., 2004; Todar, 2007; Krammer et al., 2008). Some of these metabolic wastes can be harmful to other living microorganisms in the ecosystem.

\section{Conclusion}

Although the investigation has been carried out in the mesocosm, the results suggest that the abundance dynamics of microorganisms in groundwater might initially show a decrease in abundance followed by an increase. Moreover, temporal variations of bacterial abundance in groundwater which have been widely reported in the literature might be due to the in situ inactivation or growth of many cells, in addition to other phenomena such as dilution by infiltrating water, or cell retention on geochemical particles in suspension. This will depend on the microbial group investigated.

\section{References}

ALDÉN L, DEMOLING F and BAATH E (2001) Rapid method of determining factors limiting bacterial growth in soil. Appl. Environ. Microbiol. 67 1830-1838.

ALFREIDER A, LOFERER-KRÖSSBACHER M and PSENNER $R$ (2001) Influence of artificial groundwater lakes on the abundance and activity of bacteria in adjacent subsurface systems. Limnologica - Ecol. Manage. Inland Waters 31 (4) 249-255.

APHA (1998) Standard Methods for the Examination of Water and Wastewater. American Public Health Association/American Water Works Association/Water Environment Federation, Washington DC. $1150 \mathrm{pp}$.

BACHELIER G (1959) Etude pédologique des sols de Yaoundé. Contribution à l'étude de la pédogenèse des sols ferralitiques. Agronomie Tropicale 19 279-305.

BAILEY NTJ (1981) Statistical Methods in Biology. Hodder and Stoughton, London. 216 pp.

BENGTSSON G (1989) Growth and metabolic flexibility in groundwater bacteria. Microb. Ecol. 18 235-248.

BENYEHUDA G, COOMBS J, WARD PL, BALKWILL D and BARKAY T (2003) Metal resistance among aerobic chemoheterotrophic bacteria from the deep terrestrial subsurface. Can. J. Microbiol. 49 151-156.

DZEDA B, KAISER M. and MACH S (1998) Bacteria and groundwater. Soil and groundwater pollution. Civil Engineering Dept., Virginia Tech.URL: http://www.cee.vt.edu/program-areas/environmental/teach/gwprimer/bacteria.html (Accessed 25 March 2009).

FALLON A and PERRI K (1996) Pathogen survival and transport in groundwater. URL: http://www.cee.vt.edu/ewr/environmental/ teach/gwprimer/pathogen/pathogen.html (Accessed 5 June 2009).

FENCHEL T (2001) Micoorganisms (microbes), role of. Encyclopedia of Biodiversiy 4 207-219.

FUSCONI R and GODINHO MJL (1999) Bacteria and protozoa populations in groundwater in a landfill area in São Carlos, SP. Revista de Microbiologia 30 196-202.

GILBERT J, DANIELOPOL DL and STANFORD JA (1994) Groundwater Ecology. Academic Press, San Diego. 583 pp.

HARVEY RW and GEORGE LH (1987) Growth determinations for unattached bacteria in contaminated aquifer. Appl. Environ. Microbiol. 53 (12) 2992-2996.

HOLT JG, KRIEG NR, SNEATH PHA, STALEY JT and WILLIAMS ST (2000) Bergey's Manual of Determinative Bacteriology. Lippincott Williams and Wilkins, Philadelphia. 787 pp.

KINNER NE, HARVEY RW, BLAKESLEE K, NOVARINO G and MEEKER ID (1998) Size-selective predation on groundwater bacteria by nanoflagellates in an organic-contaminated aquifer. Appl. Environ. Microbiol. 64 (2) 618-625.

KOLTER R and LOSICK R (1998) One for all and all for one. Science $280226-227$. 
KRAMMER M, VELIMIROV B, FISCHER U, FARNLEITNER AH, HERZIG A and KIRSCHNER AKT (2008) Growth response of soda lake bacterial communities to simulated rainfall. Microb. Ecol. 55 (2) 194-211.

LI Y, ODUMERU JA, GRIFFITHS M and MCKELLAR RC (2006) Effect of environmental stresses on the mean and distribution of individual cell lag times of Escherichia coli O157:H7. Int. J. Food Microbiol. 110 278-285.

MAILLOUX BJ and FULLER ME (2003) Determination of in situ bacterial growth rates in aquifers and aquifer sediments. Appl. Environ. Microbiol. 69 (7) 3798-3808.

MARCHAL N, BOURDON JL and RICHARD Cl (1991) Les milieux de culture pour l'isolement et l'identification biochimique des bactéries. Doin, Paris. 509 pp.

MAYER AS, CARRIÈRE PPE, GALLO C, PENNEL KD, TAYLOR TP, WILLIAMS GA and ZHONG L (1997) Groundwater quality. Water Environ. Res. 69 778-844.

MOUSER PJ, N'GUESSAN AL, ELIFANTZ H, HOLMES DE, WILLIAMS KH, WILKINS MJ, LONG PE and LOVLEY DR (2009) Influence of heterogeneous ammonium availability on bacterial community structure and the expression of nitrogen fixation and ammonium transporter genes during in situ bioremediation of uranium-contaminated groundwater. Environ. Sci. Technol. 43 (12) 4386-4392.

NOLA M, NJINE T, SIKATI FOKO V and DJUIKOM E (2001) Distribution de Pseudomonas aeruginosa et Aeromonas hydrophila dans les eaux de la nappe phréatique superficielle en zone équatoriale au Cameroun et relations avec quelques paramètres chimiques du milieu. Rev. Sci. Eau 14 35-53.

NOLA M, NJINÉ T, DJUIKOM E and SIKATI FOKO V (2002) Faecal coliforms and faecal streptococci community in the underground water in an equatorial area in Cameroon (Central Africa): The importance of some environmental chemical factors. Water Res. 36 3289-3297.

NOLA M, DJARMAILA E, KEMKA N, CHIHIB N-E, ZÉBAZÉ
TOGOUET SH, KRIER F, SERVAIS P, HORNEZ J-P and NJINÉ $T$ (2010) Assessment of the future of heterotrophic aerobe bacteria and electrical conductivity in groundwater samples stored in household conditions at different temperatures, in the equatorial region of Central Africa. Afr. J. Microbiol. Res. 4 (20) 2055-2066.

PACHEPSKY YA, SADEGHI AM, BRADFORD SA, SHELTON, DR, GUBER AK and DAO T (2006) Transport and fate of manureborne pathogens: Modeling Perspective. Agric. Water Manage. 86 $81-92$.

REDDY KR, KHALEEL R and OVERCASH MR (1981) Behavior and transport of microbial pathogens and indicator organisms in soils treated with organic wastes. J. Environ. Qual. 10 255-266.

RODIER J (1996) L'analyse de l'eau. Dunod, Paris. 1384 pp.

SIMOES LC, SIMOES M and VIEIRA MJ (2007) Biofilm interactions between distinct bacterial genera isolated from drinking water. Appl. Environ. Microbiol. 73 (19) 6192-6200.

SUCCHEL B (1972) La répartition des pluies et des régions pluviométriques au Cameroun. Travaux et Documents de Géographie Tropicale (C-E-G-CNRS) 5 1-288.

TIAGO I, CHUNG AP and VERISSIMO A (2004) Bacterial diversity in a nonsaline alkaline environment: Heterotrophic aerobic populations. Appl. Environ. Microbiol. 70 (12) 7378-7387.

TODAR K (2007) Nutrition and growth of bacteria. URL: http://www. textbookofbacteriology.net/nutgro.html (Accessed 14 June 2008).

TOFALLIS C (2009) Least squares percentage regression. J. Mod. Appl. Stat. Meth. 7 526-534.

VAN ELSAS JD and HEIJEN CE (1990) Methods for the introduction of bacterial into soil: A review. Biol. Fertili. Soils 10 127-133.

YATES MV, STETZENBACH LD, GERBA CP and SINCLAIR NA (1990) The effect of indigenous bacteria on virus survival in ground water. J. Environ. Sci. Health, Part A 25(1) 81-100.

ZÉBAZÉ TOGOUET SH, BOUTIN CL, NJINÉ T, KEMKA N, NOLA $M$ and FOTO MENBOHAN S (2009) First data on the groundwater quality and aquatic fauna of some wells and springs from Yaounde (Cameroon). Eur. J. Water Qual. 40 51-74. 
http://dx.doi.org/10.4314/wsa.v38i5.13 Available on website http://www.wrc.org.za

ISSN 0378-4738 $($ Print $)=$ Water SA Vol. 38 No. 5 October 2012 ISSN 1816-7950 (On-line) = Water SA Vol. 38 No. 5 October 2012 